\title{
Prevalence of Triple Negative Breast Cancers from a Hospital-Based Cancer Registry in a Tertiary Care Hospital in Kerala, South India
}

\author{
Neena Mary ${ }^{1}$, Catherin Nisha ${ }^{2, *}$, Kerline Jerome ${ }^{2}$, Clint Vaz ${ }^{2}$, Vijayalaxmi Nair ${ }^{3}$ \\ ${ }^{1}$ Amala Institute of Medical Sciences, Thrissur, South India \\ ${ }^{2}$ Department of Community Medicine, Amala Institute of Medical Sciences, Thrissur, India \\ ${ }^{3}$ Department of Pathology, Amala Institute of Medical Sciences, Thrissur, India \\ Email address: \\ cathnisha@gmail.com (C. Nisha) \\ ${ }^{*}$ Corresponding author
}

\section{To cite this article:}

Neena Mary, Catherin Nisha, Kerline Jerome, Clint Vaz, Vijayalaxmi Nair. Prevalence of Triple Negative Breast Cancers from a Hospital-Based Cancer Registry in a Tertiary Care Hospital in Kerala, South India. World Journal of Public Health. Vol. 4, No. 2, 2019, pp. 43-46. doi: 10.11648/j.wjph.20190402.13

Received: June 16, 2019; Accepted: July 3, 2019; Published: July 16, 2019

\begin{abstract}
Triple-negative breast cancer (TNBC) is defined by the absence of estrogen receptor (ER), progesterone receptor (PR) and over expression of Human epidermal growth factor receptor 2 (Her2neu). They are typically high-grade tumors and occur in young females. Our study is to determine the prevalence of triple negative breast cancers from a hospital-based cancer registry in the year 2016. This is a retrospective, descriptive study where secondary data analysis was done, by obtaining data from the hospital-based immunohistochemistry (IHC) register. The Estrogen receptor, Progesterone receptor and Her2neu receptor status of the breast cancers which presented to the hospital and the referral cases received for IHC in the year 2016 was obtained from the register which totaled to 335 cases. The type of breast carcinoma was also noted. In our study the mean age of breast cancer patients was $56.2 \pm 12.387$ years. There was 331 (98.8\%) females among the study population. The most prevalent type of breast cancer was invasive ductal carcinoma which was 330 (98.5\%). We also found out the prevalence of mono negative, bi negative and triple negative breast cancers. The prevalence of triple negative breast cancer was $58(17.31 \%)$. There was no statistically significant difference found between prevalence of triple negative breast cancer and age. Our study showed that the prevalence of triple negative receptor breast was $17.31 \%$ among the study population. This study would serve as a baseline study for further research to open up new therapeutic possibilities.
\end{abstract}

Keywords: Immuno Histo Chemistry, Triple Negative Breast Cancer, Hospital Based Cancer Registry, South India

\section{Introduction}

Cancer is rampantly becoming one of the major health problems in the present era [1]. The most prevalent cancer globally among women is breast cancer and represents the second most common cause of cancer death among women [2]. More than 1.1 million cases are diagnosed each year and more than 410,000 patients die of the disease worldwide [3]. The receptor status of breast cancer is assessed by immunohistochemistry (IHC) based on the presence of Estrogen receptors (ER), Progesterone receptors (PR), and human epidermal growth factor receptor (Her2neu) [4].
Triple-negative breast cancers (TNBCs) are defined as tumors that lack expression of Estrogen receptor, Progesterone receptor, and Her2neu [5]. Generally $10-24 \%$ of invasive breast cancers fall into this category. TNBCs are typically high-grade tumors, although low-grade tumors do occur [6]. Breast cancers occurring in patients with germ line BRCA1 mutations are often triple negative. TNBCs have higher rates of occurrence among young females [6]. A similar type of triple-negative breast cancer is basal-like breast cancer (BLBC). This molecular subtype of breast cancer is characterized by a gene-expression profile that is similar to that of the basal-myoepithelial layer of the normal breast tissue. Multiple studies have indicated that triple negative and 
basal-like breast cancers are associated with an adverse prognosis. The shape of the survival curve for patients with triple-negative or basal-like breast cancer shows a sharp decrease in survival during the first 3 to 5 years after diagnosis [7]. Among the therapeutic agents Poly (ADP-ribose) polymerase inhibitors, Angiogenesis inhibitors, EGFR-targeted agents, src kinase and mTOR inhibitors are being actively investigated in clinical trials in patients with TNBC and/or BRCA1-associated tumors. Even though these tumors respond to conventional chemotherapy, they relapse more frequently [6].

The prevalence of a disease is among the most fundamental measures in epidemiology. It signifies the burden of disease in a population over a period and represented as the number of people affected [8]. Hence information about prevalence would clearly serve as a basis for further research for new therapeutic possibilities for these hard to beat breast cancers. Also, data from registry is less used for research purpose. Therefore, we decided to take up this study to determine the prevalence of triple negative breast cancer from a hospital-based cancer registry in a tertiary care hospital in Kerala, South India.

\section{Methodology}

\subsection{Study Design}

This is a retrospective descriptive study.

\subsection{Study Setting}

Tertiary care cancer specialty hospital in Kerala, South India.

\subsubsection{Study Population}

Breast Cancer patients attending a tertiary care hospital in Kerala, South India whose IHC has been done in the year 2016.

\subsubsection{Data Collection}

A total of 335 cases had been recoded in the IHC register during the year 2016. Prior permission was obtained from the management of the Institution to collect required data from the patient data file. Permission was also taken from the Head of the Department of Pathology to access the data from the department register. The demographic details including name, age and gender were collected. The IHC results of breast cancer cases which presented to the hospital as well as the referred breast cancer cases for which IHC was done in the hospital were recorded. The IHC data included Estrogen receptor, Progesterone receptor and Her2neu receptor status. It was recorded manually as positive, negative or equivocal. The corresponding type of breast carcinoma was also noted. In case if the data was not available for any one of the receptors it was recorded as data not available. The observations were coded as numbers.

\subsubsection{Data Analysis}

The data were entered in Microsoft Excel, and analyzed using SPSS version 17.0. Frequency, mean, standard deviation and chi-square test were used for analysis.

\section{Results}

\subsection{Socio demography of Study Population}

The IHC status of 335 breast cancer patients who presented to the hospital and the biopsy sections received from other hospitals in Kerala in the year 2016 was obtained of which 331 $(98.8 \%)$ patients were females and $4(1.2 \%)$ were males.

Table 1. Demographic details of study population.

\begin{tabular}{llll}
\hline \multirow{2}{*}{ Age in years } & Sex & \multicolumn{2}{c}{ Total } \\
\cline { 2 - 3 } & Female & Male & \\
\hline$\leq 49$ & $105(31.7 \%)$ & 0 & $105(31.3 \%)$ \\
$50-59$ & $102(30.8 \%)$ & 0 & $102(30.4 \%)$ \\
$60-69$ & $74(22.35 \%)$ & $1(25 \%)$ & $75(22.4 \%)$ \\
$\geq 70$ & $50(15.1 \%)$ & $3(75 \%)$ & $53(15.8 \%)$ \\
Total & $331(98.8 \%)$ & $4(1.2 \%)$ & 335 \\
\hline
\end{tabular}

\subsection{Types of Breast Cancer and Receptor Profile}

With regard to type of breast cancer $98.5 \%$ of the breast cancers were invasive ductal type of cancer as shown in table 2.

Table 2. Type of breast carcinoma.

\begin{tabular}{lll}
\hline TYPE OF CARCINOMA & FREQUENCY & PERCENTAGE \\
\hline Invasive ductal & 330 & $98.5 \%$ \\
Colloid & 2 & $0.6 \%$ \\
Invasive lobular & 2 & $0.6 \%$ \\
Inflammatory & 1 & $0.3 \%$ \\
\hline
\end{tabular}

The mean age was $56.2 \pm 12.4$ years. Majority were in the age group less than or equal to 49 years $(31.3 \%)$. The demographic factors of the study population are depicted in Table 1.

Regarding the receptor status, the number of Estrogen receptor negative cases were 144 (43\%), Progesterone receptor negative cases were $183(54.5 \%)$. Her2neu negative cases were 178 (53.1\%).

Table 3. The receptor status of the breast cancer.

\begin{tabular}{|c|c|c|c|c|}
\hline RECEPTOR & POSITIVE & NEGATIVE & EQUIVOCAL & DATA NIL \\
\hline ESTROGEN RECEPTOR & $191(57 \%)$ & $144(43 \%)$ & 0 & 0 \\
\hline PROGESTERONE RECEPTOR & $152(45.4 \%)$ & $183(54.6 \%)$ & 0 & 0 \\
\hline Human epidermal growth Factor receptor & $124(37 \%)$ & $178(53.1 \%)$ & $24(7.2 \%)$ & $9(2.7 \%)$ \\
\hline
\end{tabular}

The total number of cases with both estrogen and progesterone receptor negative (bi negative) was 70 (20.9\%). 
Table 4. Molecular subtypes of breast cancer.

\begin{tabular}{lllll}
\hline Type & ER & PR & HER2NEU & FREQUENCY \\
\hline \multirow{2}{*}{ Luminal A } & POS & POS & NEG & $97(28.96 \%)$ \\
& POS & NEG & NEG & $21(6.27 \%)$ \\
Luminal B & POS & POS & POS & $39(11.64 \%)$ \\
Triple negative & NOS & NEG & POS & $13(3.88 \%)$ \\
Bi negative & NEG & NEG & NEG & $58(17.31 \%)$ \\
Others & NEG & & POS & $70(20.9 \%)$ \\
TOTAL & & & $37(11.04 \%)$ \\
\hline
\end{tabular}

There were $24(7.2 \%)$ equivocal cases of Her2neu and 9 $(2.7 \%)$ cases where data was not available. [Table 3]

The overall prevalence of triple negative breast cancer was found to be $58(17.31 \%)$. [Table 4]

\subsection{Triple Negative Breast Cancer and Age}

Among the 58 triple negative cases, most of the patients come under the age group less than or equal to 49 years (41.3\%). The chi-square $\mathrm{p}$-value was calculated $(\mathrm{P}<0.05 \mathrm{chi}$ square $=0.203$ ). This indicates there is no statistically significant relation between age and triple negative breast cancer. [Table 5].

Table 5. Age distribution among triple negative breast cancer.

\begin{tabular}{ll}
\hline Age group & Triple negative \\
\hline$\leq 49$ & $24(41.3 \%)$ \\
$50-59$ & $17(29.31 \%)$ \\
$60-69$ & $8(13.7 \%)$ \\
$\geq 70$ & $9(15.5 \%)$ \\
Total & $58(100 \%)$ \\
\hline
\end{tabular}

\section{Discussion}

This study comprised of 335 cases of breast cancer. The mean age of the study population was 56.2 years. A study conducted in Chennai in 2011 showed a mean age of breast cancer patients as 53.8 years [9]. Study conducted in Saudi Arabia in 2014 showed a mean age of 53.7 years which is comparable to our study [10]. Mean age of Indian breast cancer patients are found to be lower when compared to the Western countries with an average difference of one decade [11].

Our study had 4 male patients (1.2\%) and in a study conducted in South India males constituted $1.25 \%$ thus we find a similarity in the distribution [12]. Male breast carcinomas constitute $1 \%$ of total breast cancers as revealed in a study conducted in the western countries in 2006 [13].

With regard to Estrogen receptor negativity (ER-ve) and Progesterone receptor negativity (PR-ve), our study when compared to similar studies done in Chennai and Karnataka, our study showed ER-ve $43 \%$ and frequency of PR -ve as $54.6 \%$, which was a Middleton result, as the study from Chennai showed ER-ve $40.8 \%$ and PR -ve cases $48.9 \%$ and results of Karnataka study depicted a higher value of ER-ve $63.4 \%$ and PR-ve $68.2 \%$ [9, 14]. While a study conducted in Jordan showed $49.1 \%$ ER -ve cases and $42.5 \%$ PR -ve cases which are quite similar to our study [15].
The number of Her2neu negative cases was $53.1 \%$ in our study while a study conducted in Chennai showed a high value of $72.9 \%$ [9]. It was $97.6 \%$ in a study conducted in Karnataka [14]. This high value maybe because of the inclusion of Her2neu equivocal cases as negative receptor status cases. A study conducted in Jordan revealed 55.8\% Her2neu negative cases which are similar to the result in our population [15].

The ER - ve and PR-ve (bi-negative) cases in our study subjects was $20.9 \%$ while in the study conducted in Chennai it is $36.8 \%$ [9]. A similar study conducted among Iraqi females showed $10.9 \%$ bi-negative cases [16]. In the United Arab Emirates (UAE), a study reported the incidence rate of 4.9 percent ER-ve, PR-ve and Her2neu+ve cases [17]. The research team in Saudi Arabia had concluded $11.10 \%$ ER-, PR-, HER2+cases showing a reduced prevalence among the middle east regions [10].

In our study, the overall prevalence of triple negative breast cancer was found to be $17.31 \%$. A recent study conducted in Chennai showed a result of about $25 \%$ of triple negative breast cancers [9]. Studies from Western countries have shown that triple negative tumors have constituted $14 \%$ to $29.5 \%$ of breast carcinomas and our prevalence $17.31 \%$ which falls in the range [18]. A study conducted in Saudi Arabia showed that TNBCs constituted only $9 \%$ of breast carcinomas. [10]

On correlating with age, majority of our triple-negative breast cancers occurred in females less than 49 years of age. This seems contradictory to the result obtained in a study conducted in Chennai, where most cases were above 50 years of age. [9] In a Chinese study there was a predominance of TNBCs among premenopausal age group which is similar to our study finding.[19] Also our study is in agreement with some Western studies where triple-negative breast cancer predominantly affects younger women. [20] These differences in IHC pattern rates among our study populations could be due to the small size of data obtained or due to the unexpected heterogeneity of breast cancer.

\section{Conclusion}

The mean age of breast cancer patients in our study was found to be 56.2 years with $98.8 \%$ prevalence in females and $1.25 \%$ prevalence in males. Majority of the breast cancers among the study subjects were invasive ductal type of cancer. The receptor status showed an intermediate result in our study compared to the study results in neighboring states. This study enumerates the prevalence of triple negative breast cancer in the year 2016 . There is $17.31 \%$ prevalence of triple negative 
breast cancer. Our study showed a predominant younger age group among the triple negative patients. Hence this retrospective secondary data analysis adds to the growing literature of breast cancer and also strengthens the data of TNBC.

\section{Recommendations}

This study made us realize the burden of disease prevalence in the community. So far, it is a disease entity with limited therapeutic possibility which accounts for its high prevalence and a decreasing survival curve. The key to make this a conquerable disease is a further shift in therapy and detailed knowledge of its clinical and molecular diversity and identification of predictive biomarkers. For that future studies need to be conducted to break open the sophisticated molecular mechanisms behind these breast cancers and thus discover an advanced treatment. Also, studies must be conducted with a larger study population so as to obtain a more accurate result as well as to confirm any regional variations in the prevalence.

\section{Acknowledgements}

We acknowledge the hospital management for giving permission to conduct the study.

\section{References}

[1] Babita SK, Krishnadas V, Saju C, Vidhu J, Catherin N. Prevalence of cancers from a hospital based cancer registry in a tertiary care hospital in South India. Inter J of Scient Resear and Edu 2015; 3: 4638-40.

[2] Babu GR, Lakshmi SB, Thiyagarajan JA. Epidemiological Correlates of Breast Cancer in South India. Asian pacific jour of cancer prevent 2013; 14: 5077-83.

[3] Ferlay JHC, Autier P, Sankaranarayanan R. Global Burden of Breast Cancer. Breast Can Epid 2010; 6: 1-19.

[4] Available from: https://en.m.wikipedia.org/wiki/Breast_ cancer_classification. Last accessed on December 2018.

[5] Stagg J, Allard B. Immunotherapeutic approaches in triple-negative breast cancer latest research and clinical prospects. Therap advan in medical oncol2013; 5: 169-81.

[6] Carey L, Winer E, Viale G, Cameron D, Gianni L. Triple-negative breast cancer: disease entity or title of convenience. Nat Reviews Clini Oncol 2010; 7: 683-92.
[7] William D, Foulkes WD, Smith IE, Jorge S, Reis-Filho. Triple-Negative Breast Cancer, The new Engl J of Medicin 2010; 363: 1938-48.

[8] Available from https://www.medicinenet.com/script/main/art.asp?articlekey=1 1697 last accessed on March 2019.

[9] Ambroise M, Ghosh M, Mallikarjuna VS, Kurian A. Immunohistochemical Profile of Breast Cancer Patients at a Tertiary Care Hospital in South India. Asian pacific J of Can Prevent 2011; 12: 625-29.

[10] Khabaz MN. Immunohistochemistry Subtypes (ER/PR/HER) of Breast Cancer: Where Do We Stand in the West of Saudi Arabia? Asian pacific J of Can Prevention 2014; 15: 8395-400.

[11] Stead LA, Lash TL, Sobieraj JE, Chi DD, Westrup JL, Charlot $\mathrm{M}$ et al. Triple-negative breast cancers are increased in black women regardless of age or body mass index. Breast Canc Resear 2009; 11: 18.

[12] Ghosh S, Sarkar S, Simhareddy S, Kotne S, Rao PBA, Turlapati SPV. Clinico-Morphological Profile and Receptor Status in Breast Cancer Patients in a South Indian Institution. Asian pacific J of Can Prevention 2014; 15: 7839-42.

[13] Ian SF, Alain F, Gabriel N, Hortobagyi. Male breast cancer. The Lancet 2006; 367: 595-604.

[14] Rao C, Shetty J, Kishan HL. Morphological profile and receptor status in breast carcinoma: An institutional study. Jour of Can Resear and Therap 2013; 9: 44-9.

[15] Sughayer MA, Al-Khawaja MM, Massarweh S. Prevalence of hormone receptors and HER2/neu in breast cancer cases in Jordan. Path Onco Resear 2006; 12: 83-6.

[16] Runnak MA, Hazha MA, Hemin HA, Abdulmahdi WA, Rashid MR, Hughson MD. A population.

[17] Bsed study of Kurdish breast cancer in northern Iraq: hormone receptor and HER2 status. A comparison with Arabic women and United States SEER data. BMC Womens Health 2012; 12: 16-25.

[18] Dawood S, Hu R, Homes MD, Collins LC, Schnitt SJ, Connolly $\mathrm{J}$ et al. Defining breast cancer prognosis based on molecular phenotypes: results from a large cohort study. Breast Can Resear and Treat 2011; 126: 185-92.

[19] Tischkowitz M, Brunet JS, Bégin LR, Huntsman DG, Cheang $\mathrm{MC}$, Akslen LA et al. Use of immunohistochemical markers can refine prognosis in triple negative breast cancer. BMC Cancer 2007; 7: 134.

[20] Li CY, Sheng ZS, Zhang XB, Wang P, Hou GF, Zhan J. Clinicopathological and Prognostic Characteristics of Triple Negative Breast Cancer (TNBC) in Chinese Patients: A Retrospective Study. Asian Paci Organiz for Can Preven 2013; 14: 3779-84. 